\title{
Transformações e perspectivas dos agronegócios brasileiros
}

\section{John Wilkinson ${ }^{1}$}

${ }^{1}$ CPDA/DDAS/UFRRJ - Rio de Janeiro, RJ.

RESUMO - O trabalho analisa a situação dos agronegócios brasileiros na nova conjuntura global, que se caracteriza em primeiro lugar pela ascendência da China e a sua demanda para commodities agrícolas, sobretudo nas cadeias de rações onde o Mercosul, e em especial o Brasil, se torna a principal região fornecedora. Existe a ameaça de que nessa nova dinâmica o Mercosul se insere cada vez mais no comércio internacional como simples fornecedora de matéria-prima. Esse cenário se complica na medida em que seja acompanhado por uma transnacionalização das empresas líderes nesse setor. Contra isso, a expansão da fronteira agrícola para o Centro-Oeste e Norte do Brasil cria oportunidades para o surgimento de novos atores nacionais tanto nas atividades de processamento como de logística e comércio. A importância de mercados para produtos diferenciados tampouco desaparece porque, se os mercados do Norte se tornam menos dinâmicos, surge uma nova classe média em âmbito global. Acompanhamos uma dinamização do mercado doméstico brasileiro que faz parte desse mesmo processo global. Para aproveitar essas oportunidades, porém, o Brasil precisa negociar um contexto mais complexo, onde a liderança em pesquisa e inovação de desloca para as empresas transnacionais.

Palavras-chave: agroindústria brasileira, mercados globais de commodities, transnacionalização

\section{Transformations and perspectives of Brazilian agribusiness}

\begin{abstract}
This article analyzes the situation of Brazilian agribusiness worldwide, which is characterized primarily by the ascendancy of China and its demand for agricultural commodities, especially the feed chains where the Mercosur, and especially Brazil, becomes the main supplier. There is the threat that in this new dynamics Mercosur falls increasingly on international trade as a mere supplier of raw materials. This scenario is complicated due to the transnationalization of the leading companies in this sector. Against this, the agricultural expansion into the Midwest and Northern Brazil creates opportunities for the raise of new segments in both domestic processing activities such as logistics and trade. The importance of markets for differentiated products either disappears because if the Northern markets become less dynamic, a new middle class globally appears. We followed a dynamic of domestic market of that overall process. To seize these opportunities, however, Brazil has to negotiate a more complex environment, where leadership in research and innovation goes to transnational corporations.
\end{abstract}

Key Words: Brazilian agribusiness, global commodity markets, transnationalization

\section{Introdução}

Vários estudos sobre as tendências de longo prazo dos agronegócios (2007-2017) foram divulgados em 2008 por organismos internacionais e centros de pesquisa acadêmica - OECD/FAO, USDA, FAPRI, IFPRI. Afinada com esses estudos, a Assessoria de Gestão Estratégica do MAPA elaborou as suas próprias projeções para o Brasil, cobrindo o mesmo período, as quais receberam nova versão em fevereiro de 2009. Infelizmente, o ano 2008 viu um conjunto de acontecimentos que coloca em questão muitos dos pressupostos desses estudos. Logo em 2008, o Governo norte-americano aumentou em cinco vezes as metas de produção de biocombustíveis. Com a perspectiva de dedicar
40\% da sua produção de milho para bioetanol, a dinâmica dos mercados de grãos, oleaginosos e o complexo de proteína animal mudou por completo não apenas nos Estados Unidos, mas globalmente, dado o peso da produção norteamericana nos mercados internacionais. Essa perturbação nas projeções foi rapidamente ofuscada pela explosão nos preços das commodities, especialmente commodities agrícolas, muitas delas dobrando em preço no espaço de um ano. Muitas foram as causas identificadas, tanto dentro do setor (a queda de estoques, secas prolongadas) como nas suas relações inter-setoriais (dependência do petróleo, direta e indiretamente) e na sua nova integração como o setor financeiro (sobretudo na bolsa de futuros). Antes do final do ano, o alto nos preços se reverteu, não como um 
sinal de retorno à normalidade, mas em resposta à crise que agora colocou em cheque projeções sobre as taxas de crescimento, o ritmo e a natureza de investimentos e a própria regulação dos mercados dos agronegócios com o aumento de protecionismo e as estratégias unilaterais de segurança alimentar e energética.

Como resultado disso as perspectivas de investimentos de curto/médio prazo tanto no mundo como no Brasil dependem da evolução da crise que já assumiu as dimensões de uma recessão global. Não se trata apenas de postergar planos de governos e de atores privados. Envolve também mudanças de estratégia que podem afetar o quadro de longo prazo. Aquisições a fusões começam a predominar no lugar de novos investimentos, IPOs na bolsa e fundos de investimento recuam, parcialmente compensadas por uma atuação maior de órgoes públicos, empresas domésticas se tornam alvos mais fáceis das investidas de global players, e multilateralismo e o comércio internacional cedem frente estratégias “neo-coloniais” de aprovisionamento. Já existem indícios que novas pautas - orgânicos - e novos hábitos - refeições fora de casa - de consumo estão sendo freadas. Ainda é cedo para avaliar o impacto da crise sobre o ritmo de iniciativas em torno do padrão tecnológico dos agronegócios - sobretudo aquelas relacionadas a investimentos, regulações, acordos “verdes” e agroenergia.

Por outro lado, o conjunto dos estudos mencionados acima identificou tendências influenciando a dinâmica dos agronegócios que dificilmente serão revertidas pela crise muito embora possam afetar a velocidade e abrangência dessas transformações. Curiosamente, portanto, as perspectivas de longo prazo se tornam mais confiáveis. Em todos os estudos se destacam taxas de crescimento econômico maiores nos países em desenvolvimento e, sobretudo nos grandes países em desenvolvimento. A isso se acrescentam taxas maiores de crescimento demográfico, com quase todo o aumento populacional acontecendo nesses países em desenvolvimento. E em terceiro lugar, essas duas tendências acontecem num processo de urbanização acelerada que atinge o conjunto dos países em desenvolvimento e implica em profundas mudanças nos hábitos alimentares, caracterizadas, sobretudo por uma transição para uma dieta de proteína animal.

\section{A retomada de centralidade do mundo das commodities}

Um slowdown no consumo per capita de alimentos básicos já foi detectado nos países desenvolvidos a partir dos anos 80 provocando por parte das empresas estratégias de diferenciação dos produtos e segmentação dos mercados. Hoje, essas estratégias de concorrência pela “qualidade” se projetam em âmbito global. Muito mais marcante, porém para os agronegócios tem sido a retomada agora em escala global da dinâmica dos mercados de commodities com a nova centralidade de populosos middleincome países e o surgimento de uma classe média global calculada a contar por um terço da população mundial por volta de 2030, algo em torno de dois bilhões de pessoas.

Nessa dinâmica, a Ásia se torna o eixo do crescimento no consumo dos alimentos típicos da dieta urbana.da nova classe média e o Cone Sul o eixo de crescimento da produção das commodities que servem como inputs para essa dieta. O ano 2005, quando o Brasil pela primeira vez exportou mais produtos dos agronegócios para o Sul do que para os países do Norte, marcou bem essa nova dinâmica. Dentro da Ásia, é a China que concentra o aumento dos fluxos comerciais dessas commodities, sobretudo do complexo soja, deslocando a Europa nesse papel. As especificidades do consumo alimentar - freqüência, perecibilidade, hábitos culturais - estimula a presença direta das empresas nos mercados domésticos. Em outros casos, são as políticas do Estado e várias formas de protecionismo que incentivam investimentos nos mercados domésticos. No caso dos EUA as vendas das filiais das suas empresas agroalimentares são quatro vezes o valor das suas exportações de alimentos. Assim, a China e outros países asiáticos agora se tornaram o principal alvo de investimento externo direto (IED) abrangendo todos os elos que compõem os agronegócios. Diferentemente do que no caso da América Latina que tinha uma urbanização precoce, uma maior proximidade cultural com Europa e os Estados Unidos, bem como Estados que adaptaram os seus mercados para a sua integração global, a China e outros países da Ásia têm Estados autoritários e/ ou independentes capazes de impor severas regras sobre investimentos estrangeiros e acesso aos seus mercados. Ao mesmo tempo, os seus hábitos alimentares colocam grandes desafios para os atuais global players. Mesmo nos países do Conesul onde a transnacionalização já se encontra em fase avançada, empresas nacionais estão alcançando uma atuação regional e incipientemente global. Podemos esperar, portanto, como aconteceu também no caso do Japão, o surgimento de novos atores globais para contestar ou compartilhar a hegemonia das atuais empresas líderes.

Nesse cenário, o Brasil se destaca como o novo pólo de exportações de um leque amplo de commodities agrícolas. Em 2007, o Brasil foi o líder mundial nas exportações de carne vermelha, aves, açúcar, café e suco de laranja, o segundo maior exportador de soja em grão, farelo e óleo de soja, o terceiro maior exportador de milho e o quarto maior exportador de algodão e suínos. O Brasil tem uma área cultivável de 340 milhões de hectares, dos quais apenas 63 milhões são atualmente dedicados a cultivos, e 200 milhões 
de hectares em regime de pasto. Com base nesse cálculo algo em torno de 77 milhões de hectares de fronteira agrícola são disponíveis sem tocar na floresta amazônica ou no Pantanal. Além disso, avanços em produtividade vão liberar grandes áreas atualmente dedicadas a pasto. Deve se agregar a isso também as fronteiras agrícolas dos países vizinhos Bolívia, Paraguai e Uruguai - bem como a crescente integração de setores agroindustriais chaves de Argentina e Brasil. Embora os mercados do Norte permaneçam chaves, em 2005 pela primeira vez os mercados dos países em desenvolvimento contaram por mais de $50 \%$ do valor das exportações agroalimentares do Brasil. Com uma população de 190 milhões que deve chegar a 240 milhões antes de estacionar, $80 \%$ da qual classificada como urbana e com renda per capita de US\$10 mil PPP, o mercado doméstico brasileiro também se tornou um alvo privilegiado de IED, cedendo em tamanho apenas para a China e a Índia entre os países emergentes.

As súbitas oscilações extremas nos preços das principais commodities alimentares e energéticas durante 2007-8 ressaltaram algumas das novas tendências que vão influenciar a evolução desses mercados no próximo período. Em primeiro lugar, o peso dos produtos energéticos, tanto diretamente na forma de etanol e biodiesel quanto indiretamente como insumos, na evolução dos preços agrícolas. Os principais mercados de grãos são agora diretamente influenciados por políticas energéticas. Em segundo lugar, o crescente peso da China desloca a União Européia como eixo global da demanda, e o Cone Sul desloca América do Norte no lado da oferta. Em terceiro lugar, um aumento acentuado de incerteza em torno dos impactos de estresse climático, expresso na maior volatilidade das safras agrícolas. Quarto, um maior envolvimento de fundos especulativos nas bolsas de commodities agrícolas. E quinto uma fragilização de multilateralismo como estratégia de segurança alimentar em favor de acordos bilaterais de acesso a recursos naturais renováveis por parte de Estados mais assertivos. Todas essas novas características vão influenciar, mas não anular as tendências de médio e de longo prazo.

\section{China e Brasil: a nova dinâmica da soja}

Em todas as projeções de longo prazo é o complexo de soja que assume a liderança no comércio internacional deslocando trigo, milho e outros grãos. Segundo a USDA todos os componentes desse complexo vão crescer a taxas anuais acima de 3\% e a China será responsável por $80 \%$ do crescimento nas importações mundiais. O maior beneficiário desse aumento será o Brasil avançando dos atuais 30\% para mais de $40 \%$ do total de exportações de soja em grão, o que implica em dobrar as suas embarcações. Argentina, por sua vez, ocupa cada vez mais espaço no comércio mundial de rações, cujo mercado principal é a União Européia, se tornando o principal pólo de esmagamento no Cone-Sul. Embora as projeções para a expansão de exportações de carnes sejam mais baixas do que para soja é o Brasil que aumenta a sua posição de liderança também em aves e carne bovina e é responsável para a maior parte da expansão de carne suína ao longo desse período. Segundo as projeções do MAPA, o Brasil vai triplicar a sua produção de etanol e aumentar em média $50 \%$ do conjunto dos seus grãos (inclusive de trigo) e carnes no período até 2017/18. O dinamismo do seu mercado interno permite a consolidação desses setores em pautas mais sofisticados de demanda industrializados no caso de carnes e ingredientes no caso de soja - abrindo a perspectiva de contestar a liderança também nessas rubricas tanto por meio de exportações quanto pela transnacionalização das suas empresas líderes. A convergência entre mercados alimentares e energéticos aponta no mesmo sentido, transformando não apenas a dinâmica do setor de açúcar, mas também da soja na forma de biodiesel.

O que isso implica para o Brasil? Dentro da ótica de vantagens comparativas entre países a análise acima apontaria, sobretudo para a necessidade de aprimorar sistemas de infraestrutura, logística e comunicações e adequar o quadro regulatório às exigências de qualidade, sanidade e dos acordos sobre o meio-ambiente, direitos humanos e bem-estar animal. Nessa ótica, pode também assinalar para a necessidade de apoiar P\&D para complementar as atividades do setor privado. Tudo isso é necessário e certamente aumentaria o papel de Brasil como principal ofertante global de matéria prima com reflexos positivos sobre o balanço comercial e a geração de divisas. Mas, mesmo o mundo de commodities é um mundo de estratégias, de atores e de interesses. À visão a partir de países e suas vantagens comparativas, devemos acrescentar aquela vinda da tradição de análise que entende a dinâmica econômica a partir da ótica de "cadeias globais de valor", onde o comércio é largamente controlado por poucos atores estratégicos e onde o comércio intra-firma e/ou coordenado por empresas líderes conta pela maior parte dos fluxo globais. Nessas análises é notória que a porcentagem de valor agregado captada em torno da matéria prima é baixa e geralmente declinante.As estratégias que decorrem dessa ótica enfatizam a necessidade de explorar as opções de avançar ao longo da cadeia. Nos últimos anos, o Brasil começa a adotar essa estratégia com as suas firmas líderes desenvolvendo marcas em torno de produtos da maior valor agregado e avançando nos mercados externos com base em 
joint-ventures aquisições e investimentos diretos, sobretudo nos setores de bebidas, carnes a açúcar/álcool.

Essa estratégia, no entanto, se encontra debilitada pelo grau de transnacionalização do sistema agroalimentar brasileiro que agora tende a se agravar no contexto de uma crise que ameaça seriamente a saúde financeira de muitas empresas no setor. Nos anos '80, as empresas líderes brasileiras atuavam em carnes e grãos e foram os maiores propulsores da nova fronteira dos cerrados. Elas dominavam o setor de esmagamento e entraram nas atividades de trading. Tudo isso sofreu um recuo na década seguinte quando os global players assumiram controle da cadeia de soja no Brasil bem como do seu comércio internacional. Hoje, o surgimento de novos atores em torno do avanço da fronteira da soja para o Centro-Oeste e o Norte, ao exigir a implementação de novos sistemas de logística, de transporte e de escoamento, abre oportunidades impares de ocupar espaços mais nobres nessa cadeia global de valor. Essas oportunidades se ampliam a medida em que surja uma nova legitimação da atuação do Estado e das suas instituições de investimento e fomento, um fator comum a todos os novos países emergentes e cada vez mais decisivo no contexto da fragilização de muiltilateralismo. A convergência entre alimentos e energia reforça as possibilidades de agir também na esfera de trading exemplificada na atuação de Petrobrás tanto em etanol quanto em biodiesel, bem como na ousada aquisição da Exxon por parte da Cosan.

Como bem têm enfatizado pesquisadores do ICONE, a competitividade de commodities agrícolas hoje depende da aplicação da fronteira dos conhecimentos de CT\&I. O sistema nacional de pesquisa agrícola coordenado por EMBRAPA foi imprescindível como fonte de inovação genética para o avanço do agronegócio brasileiro. Hoje a sua posição de liderança está colocada em questão pelo avanço das empresas globais de genética, exemplificado mais recentemente na compra das empresas de biotecnologia de cana-de-açúcar. Na mesma forma, o setor brasileiro de bens de capital para o agronegócio enfrenta a entrada de empresas estrangeiras. Assim a noção de avançar em direção ao valor agregado da cadeia envolve tantos os setores a montante quanto a jusante. Não se trata de uma oposição à transnacionalização, mas da necessidade de manter condições reais de negociação com os global players e de avançar interesses nacionais mesmo quando não coincidem com as prioridades desses global players.

A competitividade de commodities mesmo que depende de vantagens de preços não se reduz a isso, mas envolve estratégias de posicionamento. Assim, existe um cenário sobre a organização espacial global do setor de grãos em que o Cone Sul se dedica ao produto básico e indiferenciado enquanto nos Estados Unidos se desenvolvem os novos mercados segmentados para distintos tipos de cereais e oleaginosos, custom-made para fins industriais ou de consumo final diferenciado. Esses mercados que gozam de preços prêmio devem ser contestados pelo Brasil e nesse sentido o refortalecimento de nossas esmagadoras e traders regionais se torna uma prioridade. Nessa estratégia, também, os global players podem se tornar aliados, como no caso da joint-venture Solae entre Bunge e Dupont que eventualmente pode se transformar num pólo/cluster global de ingredientes de soja e já promove circuitos especializados de fornecimento de soja não-OGM. De novo, a competitividade global do Brasil se assenta também no dinamismo do seu mercado doméstico, exemplificado na importância da soja como ingrediente de base nos novos sucos, tipo light. Nada menos do que 50\% desses novos sucos vendidos no Brasil agora utilizam soja.

Uma visão sistêmica da competitividade global do agronegócio brasileiro não podia deixar de considerar a transnacionalização do setor de varejo que agora se torna o elo hegemônico do conjunto do sistema e ameaça caducar noções baseadas em cadeias de produtos, sendo acima de tudo atores transversais. Na mesma forma do nosso setor de esmagamento e de trading de grãos, os anos ' 90 viram uma rápida desnacionalização do setor de varejo de alimentos no Brasil. Hoje apenas a rede Pão de Açúcar se mantém entre as líderes, e mesmo assim como uma participação de 50\% da rede francesa, Cassino. Enquanto isso, o varejo europeu e norte-americano avança aceleradamente para controlar os novos mercados dos países emergentes. Segundo os analistas do setor, essa transnacionalização transformará a dinâmica do comércio global em vários sentidos. Em primeiro lugar, o varejo diretamente coordena cadeias de suprimentos am âmbito global, sobretudo em novas pautas dinâmicas como frutas, verduras, carnes e aqüicultura. Em segundo lugar, essas empresas começam a colocar em funcionamento redes globais de distribuição que relegam tanto os tradicionais canais de comercializaação quanto os traders para um segundo plano. E terceiro, na mesma forma que aumente alianças estratégicas entre empresas líderes de distintos segmentos (Monsanto com Cargill, Nestlé com Coca-Cola) o varejo estabelece fornecedores privilegiados que tendem a favorece parceiros tradicionais da mesma origem. Nesse sentido, a entrada de Wal-Mart na China é interpretada como favorecendo as exportações norteamericanas de produtos processados que pode reforçar a posição do Brasil como plataforma de commodities enquanto os Estados Unidos avançam nas suas exportações de 
produtos de maior valor agregado, uma tendência já detectada pela USDA. Para evitar que o Brasil seja relegado aos segmentos menos valorizados do sistema agroalimentar global, será necessário reforçar a posição de seus próprios atores e instituições tanto privados como públicos.

Identificando grandes tendências de mudança nos agronegócios brasileiros

No conjunto dos setores dos agronegócios no Brasil existe crescente blurring das fronteiras entre produtos tradicionais e novas e entre exportações e o mercado doméstico. Nos casos do café ou do suco de laranja, por exemplo, a potencialização do mercado doméstico se torna um complemento essencial de competitividade nas exportações. Mais ainda, o mercado doméstico agora visa igualmente os segmentos de maior valor agregado e a extensão da fronteira do mercado para as classes C e D. Por outro lado, em cadeias tidas como "tradicionais", identificamos processos de segmentação e diferenciação que estão levando à sua integração nas novas pautas de consumo. Cafés finos e a cultura coffee-shop por um lado, e a mistura de laranja com outras frutas e a sua integração com a preferência para frutas frescas por outro, transformam os eixos de valor agregado em cadeias tradicionais. $\mathrm{Na}$ mesma direção, as empresas líderes começam a atuar em termos dos mercados globais combinando a maior exploração do mercado doméstico com exportações e investimentos diretos em mercados terceiros. O setor do suco de laranja inovou nesse sentido com os seus investimentos na Florida enquanto hoje é o setor de carnes que toma a dianteira, ao se transformar em líder mundial.

A noção de cadeia e análise por produto não permite captar a importância de sinergias para consolidar a competitividade dos agronegócios. Essa importância de sinergias se estende também a combinação de estratégias de commodities com a busca de competitividade também em mercados diferenciados. Em relação a sinergias entre cadeias e produtos, vimos como a soja serve crescentemente como a base dos novos sucos, dinamizados pelo desenvolvimento da fruticultura diversificada, levando à entrada de empresas de soja nesse setor ao mesmo tempo em que a soja também se confunde com os lácteos. Novas sinergias estão se confirmando também entre o setor de carnes e de lácteos. As vantagens comparativas brasileiras e a maturidade do seu setor agroindustrial levam à renovação de culturas quase abandonadas, com o trigo e o algodão, e o alcance de competitividade internacional em atividades antes deficitárias ou restritas à produção doméstica. O caso mais notável aqui é a transformação do Brasil em grande exportador do milho seguido pelo surgimento dos lácteos brasileiros também nos mercados globais. Para enfrentar mercados mais voláteis o agricultor agora dispõe de um leque maior de opções de plantio, ajudado pelo amadurecimento de sistemas de financiamento. Essas sinergias se completam com a crescente convergência entre alimentos, energia e insumos industriais que amplia as opções de mercados nas três dimensões identificadas acima - o mercado brasileiro, exportações, e investimentos diretos nos mercados de países terceiros.

Essas sinergias estão intimamente ligadas à própria redefinição do que seja uma commodity. As vantagens comparativas são apenas potenciais se não existem as competências financeiras, informacionais, científicas, tecnológicas e logísticas que transformam essas em competitividade de mercado. Nesse sentido, commodities agrícolas já são atividades de forte intensidade tecnológica. No entanto, existem distintas estratégias para a valorização das commodities.

Assim, pode-se apropriar a fronteira tecnológica no intuito de baixar custos e aumentar a produtividade dentro das limitações de mercados de produtos indiferenciados. Por outro lado, essa estratégia pode ser combinada com a busca de uma segmentação desse produto de acordo com distintas qualidades. Aqui, a mesma fronteira científica e tecnológica está sendo mobilizada, mas com a finalidade de criar mercados com novas dinâmicas cujas elasticidades e formas de organização e coordenação são bem distintas, abrindo perspectivas para o surgimento de novos atores. No caso brasileiro, esses mercados segmentados de cereais e oleaginosos podem ser ocupados por esmagadores/ traders regionais e por cooperativas. Não se deve, portanto restringir o debate em torno das commodities à questão de exportar in natura ou em forma de semi-processados. Embora importante, ela deve ser vista dentro da perspectiva do crescimento de mercados segmentados onde ingredientes se tornam mais tailor made de acordo com o avanço de um sistema alimentar orientado ao desenvolvimento de qualidades nutricionais e funcionais cada vez mais diferenciadas. É emblemático nesse sentido que os próprios global players agora se definem como empresas de fornecimento de serviços e ingredientes nutricionais e não mais como traders.

Ficou evidente a importância do desenho de novos instrumentos financeiros e o estabelecimento de uma nova relação com o capital financeiro para respaldar os agronegócios no próximo período. A crise nos mercados alimentares e energéticos teve um componente de fatores climáticos. Essa crescente vulnerabilidade a riscos climáticos agora afeta a produção brasileira diretamente - 
mais dramaticamente na prolongada seca no Rio Grande do Sul. Ela exerce importantes impactos indiretos também ao aumentar a volatilidade dos preços globais e promover medidas de protecionismo, motivadas por preocupações de segurança alimentar. Ao mesmo tempo, a crise financeira ressaltou a necessidade de criar mecanismos mais estáveis de financiamento para os agronegócios e, sobretudo novos mecanismos financeiros de seguro agrícola.

No período mais recente, o setor financeiro tem se envolvido mais nos agronegócios. Nos grãos e oleaginosos novos papeis têm sido elaborados para viabilizar o mercado de futuros e garantir financiamento antecipado. Ao mesmo tempo, existe um maior envolvimento dos grandes traders no financiamento da safra. O capital financeiro também está mais diretamente presente como no surgimento de incorporadoras que compram terras e preparam a fazenda para uso imediato por parte de futuros compradores. Esse tipo de iniciativa pode ser um instrumento muito útil para aumentar a rapidez de expansão da fronteira agrícola, decisiva para a manutenção do Brasil na liderança dos mercados globais de commodities. Tenderia, porém, a favorecer a integração de terras com base em cálculos de retorno financeiro que podem entrar em choque com estratégias de zoneamento. Assim, o avanço dessa financeirização fundiária deve ser acompanhado por mecanismos de regulação que o subordina a critérios consensuados de zoneamento.

Muito menos útil, porém, tem sido a incorporação do capital financeiro nos agonegócios por fins especulativos. Já vimos isso na década de '90 no caso do “rei da soja” com a sua mega-fazenda, Itamaraty, agora transformada em assentamento de reforma agrária. Podemos estar agora testemunhando o mesmo no caso da pecuária com o tipo de mega investimentos em fazendas exemplificado pelo grupo Dantas no estado do Pará. Trata-se da maior operação de gado do mundo com a perspectiva de ter meio milhão de cabeças. Ao invés do capital financeiro operar nessa maneira nos agronegócios, condicionando o seu envolvimento às oportunidades de retorno de curto prazo parece mais importante que todo o expertise da nova geração de capital financeiro no Brasil fosse utilizado para desenvolver instrumentos financeiros que fortaleçam os agronegócios como um tudo. Prioridades aqui seriam um sistema de seguro agrícola, mecanismos de financiamento, e inclusive a consolidação de bancos por parte das empresas líderes, que podem aumentar a autonomia dos agronegócios em relação aos grandes traders e abrir perspectivas mais ambiciosas para o Brasil no comércio global

Novas estratégias precisam ser desenvolvidas em relação à fronteira tecnológica da genética, tanto vegetal quanto animal, e às novas tecnologias em torno da produção de ingredientes nutricionais e funcionais. O fato de o Brasil ter demorado muito mais na adoção de sementes transgênicas permitiu que o sistema nacional de pesquisa coordenado pela EMBRAPA mantivesse o seu papel de liderança no lançamento de novas variedades e, sobretudo na sua difusão com base na promoção de novas formas de parcerias com cooperativas e associações de produtores.

Hoje, porém, com a liberação dos transgênicos que agora dominam a soja e começam a ser adotados para algodão, milho e cana-de-açúcar, a vantagem passou decisivamente para o setor privado dos global players. Essa situação é mais crítica no contexto do desenvolvimento de mercados segmentados e produtos diferenciados a partir de variedades com características especiais. Mesmo que nem todas essas variedades sejam transgênicas, todas se beneficiam dos conhecimentos e métodos das novas biotecnologias e são protegidas por patentes. Mais ainda, essas especialidades são geralmente desenvolvidas com base em alianças estratégicas entre o setor de sementes e os processadores/traders criando redes de difícil acesso. É crítico que o Brasil avance nesses mercados como também na nova fronteira genética agora aberta na luta contra condições de estresse provocadas por mudanças climáticas. O perigo é que o sistema nacional de pesquisa seja relegado ao papel importante, mas secundário, de adaptação agronômica de variedades cujo valor agregado está embutido nas patentes das grandes empresas.

O importante é que o sistema nacional avance na consolidação de competências nessa fronteira tecnológica em primeiro lugar para melhor negociar com os global players. Nesse sentido, o ideal seria a consolidação de parcerias que levassem progressivamente à localização da pesquisa de base em, por exemplo, soja aqui no Brasil. Ao mesmo tempo, o domínio dessa tecnologia se torna fundamental também para viabilizar a sua aplicação a cultivos de interesse do Brasil, mas não dominados pelas empresas transnacionais ou nem mesmo do interesse delas.

Por outro lado, o cacife do Brasil no mundo das biotecnologias aumentou substancialmente com o sucesso do mapeamento do genoma de produtos chaves - cana-deaçúcar sendo o mais destacado - e de pragas que atacam esses produtos como no caso do cancro cítrico. Essas pesquisas cuja coordenação tem estado a cargo de centros universitários, permitem entre outros benefícios, uma aceleração na identificação de qualidades genéticas buscadas e posicionam o Brasil com um importante parceiro nesse ramo de pesquisa, aumentando a atratividade de desenvolver pesquisa no Brasil. 
Um desdobramento direto do sucesso dos projetos sobre a genoma da cana foi o desenvolvimento de uma estrutura tipo venture capital por parte de Votorantim da qual saíram duas empresas aplicando essa fronteira tecnológica a cana. No final de 2008 essas empresas foram compradas por Monsanto marcando a entrada desse global player na cana-de-açúcar. Mesmo que isso possa representar um recuo na consolidação de uma base autônoma de pesquisa em biotecnologia não deixa de representar um avanço, porque nesse caso essa pesquisa de ponta permanece no Brasil e já se anuncia o lançamento das primeiras variedades ainda esse ano.

Na genética de animais existem dois desafios, um em relação à pecuária bovina e outro no que diz respeito a carnes brancas. No case da pecuária bovina o deslocamento da fronteira para o Centro-Oeste, e regiões do Nordeste e do Norte exige pesquisa na adaptação de raças a esses climas em condições competitivas que necessariamente inclui a qualidade gustativa do produto. Ao mesmo tempo, precisase desenvolver um domínio sobre a transferência de embriões, pré-condição para a rápida difusão de inovações genéticas. No momento, essa indústria é composta por empresas independentes o que permite acesso à essa tecnologia. Pode ser interessante, no entanto, que as empresas líderes brasileiras adquiram diretamente essa tecnologia comprando empresas estratégicas e as transformado num bem coletivo do setor. Essa estratégia parece ser ainda mais indicada no caso de carnes brancas, onde a empresa norte-americana, a maior concorrente das empresas líderes brasileiras e que já está no mercado brasileiro, detém a sua própria capacidade de desenvolver a genética de base. Seria uma prioridade para o setor no médio prazo fazer aquisições nesse setor para assegurar a sua autonomia no desenvolvimento tecnológico do setor.

No caso do desenvolvimento de especialidades dentro dos mercados de commodities, já indicamos um cenário onde o Brasil possa ser relegado à produção de grãos básicos enquanto nos Estados Unidos e no Canadá se especializam na produção de variedades com qualidades especiais para consumo intermediário ou final. Tal cenário não e, porém inevitável e longe de ser consolidado ainda. A competitividade global do conjunto do complexo de soja no Brasil e os investimentos visando especialidades aqui tanto por parte de Bunge - DuPont quanto pelo Cargill, bem como a presença de ADM criam perspectivas para o desenvolvimento no Brasil de um pólo global de produção de especialidades em grãos e oleaginosos. A importância de biodiesel no Brasil reforça o estímulo de pesquisas nesse sentido. O alcance desse objetivo requer a promoção vigorosa de parcerias com as transnacionais, sobretudo em pesquisa, mas também no desenvolvimento de uma infraestrutura e um apoio para a consolidação desse pólo.

A tendência de segmentação dos mercados de commodities transforma a dinâmica de coordenação no setor. Isso vale tanto para as relações verticais ao longo das cadeias, quanto horizontais nas redes construídas para implementar novos standards de coordenação entre empresas, setores de governos, organismos internacionais, organizações da sociedade civil e os movimentos sociais associados. Essa tendência se iniciou com o surgimento simultâneo de dinâmicas de segmentação radicalmente opostas - transgênicos por um lado e orgânicos por outro, que por sua vez transformou a commodity básica numa nova categoria de "convencional", criando assim três segmentos. Inicialmente as estratégias das grandes empresas de sementes e os traders tentaram transformar as variedades transgênicas na base de um novo mercado genérico de commodities. Em grande parte isso aconteceu, sobretudo na América do Norte onde em muitas regiões mercados de orgânicos e de variedades convencionais foram inviabilizados, pela impossibilidade de assegurar a sua segregação em relação às transgênicas. A insistência da Europa na sua opção por variedades convencionais e a popularidade dos orgânicos, porém, criaram estímulos para sistemas de segregação.

Essa segregação em torno de valores que não são visíveis nos produtos em si, nem antes nem depois de consumo, chamados “bens de crença”, se aprofunda também pela incorporação de um conjunto de valores novos, sejam ligados à sustentabilidade, aos direitos humanos e trabalhistas, ou ao bem-estar animal. Espera-se que esses valores se tornem eventualmente o novo patamar mínimo de qualidade que define uma commodity. Enquanto isso não se materialize, porém, as commodities com essas características precisam ser cultivadas em forma segregada para se qualificaram para certificação. Os standards que governam a atribuição dessas certificações são palco de árduas negociações entre os global players, governos e organizações da sociedade civil. Os casos mais importantes no Brasil são os sistemas de certificação, em implantação num caso e em fase de negociação noutro, que garantem que grãos e gado não venham de regiões recém desmatadas da Amazônia.

Enquanto nesses casos, sistemas de zoneamento e rastreamento em nível de fazenda possam ser suficientes, formas muito mais sofisticadas de segregação e preservação de identidade são necessárias no caso de grãos cujas propriedades são tailor-made para finalidades especificas, 
inclusive para usos não alimentares e farmacêuticos, onde a sua entrada nos tradicionais circuitos de alimentos pode representar um grave risco. Esse tipo de produto é a base de alianças estratégicas firmadas entre empresas que ocupam distintos espaços econômicos nas cadeias agroalimentares. Já mencionamos o investimento greenfield em forma de joint-venture entre Bunge e DuPont no Brasil para a produção de isolados e concentrados protéicos de soja. Alianças do mesmo estilo existem entre Monsanto e Cargill e Novartis e ADM nos Estados Unidos e podem muito bem surgir no Brasil também. Nessas iniciativas o grão é previamente encomendado pela indústria e o seu valor agregado protegido por direitos de propriedade intelectual, deixando para trás as tradicionais formas de coordenação dos mercados de commodities.

Novas relações também se estabelecem com a agricultura a partir de contratualização dos agricultores cujas condições de produção são estreitamente controladas pelas empresas da aliança estratégica. Nesse sentido, o mundo das grandes commodities agrícolas de grãos e oleaginosos começa a adquirir o perfil dos contratos de integração como no caso de aves e suínos. À medida que segmentos cada vez mais numerosos dos mercados de commodities se incorporem nessas novas formas de coordenação, os mecanismos das bolsas bem como as formas tradicionais de intervenção dos governos cedem lugar a uma coordenação estreita entre os atores diretamente envolvidos que agora podem incluir até atores da sociedade civil, externos à cadeia produtiva.

Esse novo universo favorece a participação das cooperativas que têm condições ímpares de organizar os produtores sócios em torno de especialidades. Além de poder garantir uma rápida mobilização de produtores para encomendas específicas, a estrutura das cooperativas é ideal para a implementação e monitoria de sistemas de preservação de identidade. A segmentação dos mercados de commodities, portanto pode oferecer uma oportunidade para a revitalização do setor de cooperativismo. Já temos exemplos do seu potencial nos contratos para soja orgânica e convencional nas cooperativas do Sul. Esmagadoras regionais como Caramuru também estão promovendo esses novos mercados segmentados.

\section{Considerações Finais}

Mesmo no mundo das commodities a competitividade não se restringe a vantagens comparativas mas envolve decisões estratégicas e capacidades de liderança para se manter em mercados consolidados e construir uma presença em novos mercados. Durante um período, o ritmo de transnacionalização ameaçou reduzir os agronegócios brasileiros às vantagens dos seus recursos naturais. Hoje, o avanço da fronteira para novas regiões do país, a explosão da demanda nos países emergentes, o crescimento em importância de cadeias não visadas pelos até então global players, e mudanças importantes no quadro institucional, oferecem uma nova oportunidade para a transnacionalização desta vez de empresas brasileiras.

A demanda dos países emergentes tem dado um novo fôlego ao ciclo de vida das grandes commodities grãos, oleaginosos e de proteína animal. Esse desenvolvimento, no entanto, não eliminou a importância da diferenciação e da segmentação dos mercados agroalimentares. Pelo contrário, a consolidação de uma classe média de centenas de milhões nesses países emergentes amplia também a perspectiva de crescimento de mercados para produtos diferenciados. Assim, o Brasil precisa manter a sua promoção de novos segmentos - fruticultura, orgânicos, aqüicultura, cachaça, vinhos espumantes entre outros. Alguns desses mercados assumem o perfil de grandes commodities mas muitos dependem da ocupação dos mais variados nichos. Apesar da sua associação predominante com as grandes commodities e grandes empresas, uma das forças do agronegócio brasileiro é a diversidade dos seus atores. Ao lado das grandes empresas e das grandes fazendas, existe um segmento muito dinâmico de cooperativas que já se recuperou da crise dos anos 90. Ao mesmo tempo, amparado por organizações como SEBRAE e APEX, existe um enorme universo de pequenas e médias empresas (PME) que exploram mercados de nicho, tanto domésticos quanto de exportação. Além da sua importância na experimentação de mercados novos, as PMEs e as cooperativas são atores centrais na geração de emprego e no desenvolvimento regional em forma de clusters agroindustriais ou arranjos produtivos locais (APL).

Uma das peculiaridades do sistema agroindustrial e alimentar brasileiro é o grande peso do setor de agricultura familiar que se modernizou em forma paralela ao grande agronegócio. As relações entre esses dois setores são complexas indo desde o confronto direto sobre o acesso a terra até a integração na mesma cadeia agroindustrial ou na mesma cooperativa. Beneficiária de um Ministério próprio e de uma política nacional de apoio (PRONAF) que ganha mais força a cada ano, a agricultura familiar, mesmo com o avanço dos agronegócios, mantém uma participação relevante nos mercados de exportação e é preponderante em alguns produtos chaves para o mercado doméstico, como demonstrou o último censo do IBGE (2009). As recentes preocupações em torno de segurança alimentar bem como a perspectiva de uma integração cada vez maior das classes C\&D no sistema alimentar moderno aponta 
para a importância de reforçar a agricultura familiar para enfrentar os múltiples desafios dos mercados domésticos e globais. Deve prevalecer, portanto, prevalece um reconhecimento da maneira em que a co-existência de uma diversidade de atores se torna a forma mais eficaz de enfrentar tanto a variedade na dinâmica e na natureza dos mercados, bem como o alcance dos objetivos de geração de renda, emprego e desenvolvimento local e regional.

\section{Referências}

BANCO MUNDIAL. Multilateralism beyond Doha. Washington, 2008.

FAPRI. World Agricultural Outlook. Des Moines: Iowa State University, 2006

GOVERno fEDERAL. Política de desenvolvimento produtiva.
Disponível em: <http://www.desenvolvimento.gov.br/pdp/public/ arquivos/Apresentacao_PDP.pdf $>$

IFPRI. A pecuária até 2020: a próxima revolução alimentar. Washington, 2007.

MAPA. Projeções do Agronegócio Mundial e Brasil 2006/7 a 2017/18. Brasilia: 2008

OECD/FAO. Agricultural Outlook: 2008/2017. Paris: 2006.

RAMA, R.; WILKINSON, J. Foreign dect investment and agrifood value chains in developing countries: review of the main Issues, Commodity Market Review 2007-8. Rome: FAO

UNCTAD. Addressing the global food crisis. Vienna: United Nations, 2008.

USDA. USDA Agricultural Baseline Projections to 2016. Washington: 2008.

Von BRAUN, J. The world food situation: new driving forces and required actions. Washington: IFPRI, 2007.

WILKINSON, J. The food processing industry, globalization and developing countries. Journal of Agricultural and Development Economics, v.1, n.2, 2004.

WILKINSON, J. Mercados, redes e valores. UFRGC Editora, 2008. 